ceed far enough down the tube to be received by the second telescope, and so transmitted to the eye.)

In modern submarines the tube has a length of from $\mathrm{x} 6$ to $24 \mathrm{ft}$, the diameter is from 6 to 9 in., while the field of view is about $65^{\circ}$. In order that objects shall look their real size, it is necessary to give a magnification of one and a quarter to one and a half.

Fig. 3 gives an illustration of a periscope in which three telescope systems are employed. The drawing is made from information published by Messrs. Goerz ${ }^{1}$ of Berlin, and relates to periscopes made by them. It is, of course, undesirable to give any details of English periscopes at the present time.

An outer tube has a spherical glass cover. In the inner tube is the optical system, which can be

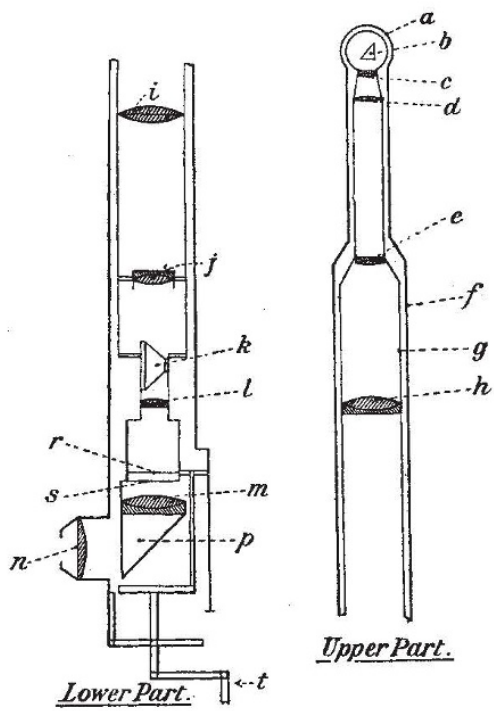

Fic. 3.- $a$, Glass cover ; $b$, prism ; $c, d$, and $\epsilon$, lenses of reversed telescope $: f$, outer tube; $g$, inner tube; $h, i$, and $j$, lenses of second telescope $; k$, reversing prism $; l, m$, and $n$, lenses of third telescope; $\not$, prism; $r$ and $s$, pointer and scale; $t$, rotating mechanism.

image given by the system is correctly at the (4) A telescope giving a magnification of about three.

This telescope includes a fixed eye piece and prism, so arranged that the observer looks horizontally at the object. At the focus of the eye piece are placed a scale and pointer to show the bearing of the object sighted, and a ruling to allow the distance to be estimated when the size of the object is known.

By the aid of a subsidiary system, special parts of the field can be further magnified to allow of objects being examined in more detail.

The continued use of the periscope is very trying to the eye, so that devices have been used to throw the image on to a ground glass screen. The ordinary eye piece and ground glass systems are made interchangeable, so that the observer can readily pass from one to the other; he may

I Dr. Weichert, Jabrbuch der Schiffsbautechnischen Gesellschaft, 19r4. No. 2368, voL. 95] observe with the ground glass in the ordinary way, but examine special objects with the ordinary eye piece.

The field of view of the periscope is still limited, and various attempts to overcome this difficulty have been made. More than one periscope can be used and the images combined to form a complete image. A recent improvement consists in the use of a ring reflector which enables a view of the whole horizon to be obtained at once. The image formed by the ring system is much distorted, but when any object is picked up it can be examined by means of the ordinary system. These two optical systems are combined in one instrument, so that the two images are seen in the one field, the image formed by the ring system surrounding the other.

But these ring periscopes are still far from perfect, their distortion making it very difficult to identify objects; and this difficulty, though not so pronounced, occurs with the ordinary periscope. The point of view from which the surface of the sea and surrounding objects are seen is one to which the eye is not generally accustomed. The conditions of lighting, too, render it difficult to distinguish objects, especially when there is mist or spray, so that the effective use of a periscope requires considerable skill and training.

Trench periscopes may be obtained from most opticians, and the following are a few typical forms :-

The Hampson, wooden stake carrying two mirrors; price $7 s .6 d$.

The Adams, jointed rod; price ros. $6 d$.

The Stanley; the support is in the form of lazy tongs, and is of a light alloy; price $25 \mathrm{~s}$.

These open-mirror types are light, portable, with good field, but the mirrors are not protected from rain, and the useful field is surrounded by bright sky.

Tube types are made by Messrs. Negretti and Zambra, Dixey, The Periscope Co., and many others; prices from $8 s$. $6 d$. to $x_{5} s$., depending on the metal tube used. In these types the field is rather limited.

Messrs. Chas. Baker and Co. supply a type with large mirrors, which can be satisfactorily used with both barrels of a binocular. In spite of the large mirrors, the type is very portable; price $30 s$.

Many makers supply types in which the optical system is incorporated with the periscope, and the prices of these range from $28 s$. to $6 l$. Ios., according to the type of optical system used.

S. D. Chalmers.

\section{OIL OF VITRIOL AS AN AGENT OF "CULTURE."}

TN a former article under this heading (NATURE, I December 3r, I9r4, vol. xciv., p. 472) we pointed out that Germany's ability to continue the war depended largely upon her power to maintain her supply of oil of vitriol, this product being absolutely indispensable in the manufacture of 
those high explosives upon which her artillery depends. We stated further that Germany's stock of the materials which are required to produce oil of vitriol is very limited, her sources of internal supply being almost negligible in comparison with the huge amounts demanded by her industries. An article by Dr. Reusch in a recent issue of the Chemiker Zeitung (vol. xxxviii., pp. r24I-43) is interesting at the present moment as showing that Germany is beginning to feel the pinch of necessity as regards this substance, and that, in view of the "reprisals" with which she is now threatened, as a consequence of her policy of "piracy and pillage," this necessity will become increasingly stringent.

We learn from Dr. Reusch's article that all export of sulphuric acid, sulphuric anhydride, and sulphurous acid from Germany is now prohibited. Before the war began she was a large importer of oil of vitriol-the imports in 1913 exceeding the exports by 65,289 metric tons-most of which came from Belgium. The total German production in 1912 is given as $1,649,68 \mathrm{r}$ metric tons, mostly made from pyrites, of which more than 80 per cent. was imported, mainly from Portugal, Spain, and France. Germany possesses deposits of this mineral, but they are of poor quality, and their working would present difficulties owing to scarcity of labour and other causes. She is now looking to Norway as a possible source, but if the policy indicated by Mr. Asquith is to be effective it should not be difficult to checkmate her action in this direction.

Another source of supply consisted in the work ing-up of zinc-blende, largely carried on in Silesia, principally on imported material, of which about 60 per cent. came from Australia alone. The only other main source would be natural sulphur imported through Italy, and principally of Sicilian origin, but here again, if the policy of "reprisals" is efficiently maintained, it should be readily possible for us to deal with this means of supply. It is interesting, in this connection, to note that in this respect, history repeats itself. During the Napoleonic wars the French occupied Sicily mainly with the view of cutting off our supply of sulphur for the manufacture of gunpowder in retaliation for our blockade of Pondicherry, upon which the enemy depended for his supply of nitre.

The sulphuric acid required for the manufacture of explosives is mainly employed in the production of nitric acid from nitrates, and from the point of view of hampering Germany in providing herself with the munitions of war it would be equally, if not more, effective to cut off her supplies of nitrates. As regards imported nitrates, and particularly Chile saltpetre, this may be practicable, and, indeed, cargoes of this material have already been stopped by our vessels on the high seas. But she has still certain internal sources of supply, as have most continental nations, and we now see that it is not for nothing that for some years past German chemists and engineers have, under the fostering influence of persons in high places, been straining every nerve to perfect possible synthetic processes of making ammonia and of converting it into nitric acid and nitrates, largely by the aid of the water-power of Norway.

Luckily for the Allies at the present juncture, certain of these processes, such as that of Ostwald, have turned out to be hopeless commercial failures, but there are others which would appear to have in them the promise of eventual and permanent success. We learn that the German Government has just introduced a Bill into the Reichstag providing for a State monopoly of the trade in nitrates for a period of seven years. The preamble explains that, at great expense, the Government has succeeded, in consequence of the stoppage of imports of Chile saltpetre, in establishing a chemical industry for the fixation of nitfates from the air, and that this industry is to be protected absolutely from all competition. Meanwhile, the price of nitrates, as of sulphuric acid, has steadily risen in Germany, and the shortage is becoming more and more pronounced. The process of depletion of sulphuric acid may be delayed by the action of the Government, which may be driven ultimately to commandeer all supplies in the interests of national defence. For the moment a certain amount is liberated in consequence of the diminished activity of various branches of chemical industry, as, for example, the dyestuff factories, and owing to the economy which has been enjoined in the manufacture of superphosphate manures, partly in consequence of the increased production of basic slag, due to the expansion of the iron industry.

$\mathrm{T}$.

PROF. H. W. LLOYD TANNER, F.R.S.

PROF. H. W. LLOYD TANNER, whose death on March 5 we announced with regret last week, was born at Burham, in Kent, on January $I 7,{ }^{2} 8_{5} \mathrm{I}$. He received his school education at Bristol Grammar School, from which he proceeded to Jesus College, Oxford. At Oxford he came under the stimulating influence of $\mathrm{Mr}$. John Griffiths, the mathematical tutor of his college. After leaving Oxford he held some educational appointments until the year I883, when the University College of South Wales and Monmouthshire was founded at Cardiff. Of this college he was appointed Professor of Mathematics and Astronomy, and he occupied the chair at Cardiff until his resignation in 1909.

Cardiff University College now forms one of the constituent colleges of the University of Wales, but the Charter of the University was not granted until ten years after the opening of the college at Cardiff. In the interval the students of the college were prepared for the degrees of the University of London, and the courses of lectures in mathematics and other subjects were necessarily framed to meet the requirements of that University. After the foundation of the University of Wales the professors in the Welsh colleges enjoyed a degree of freedom in the choice and scope of the subjects they taught which had been denied to them when their students were reading for the

NO. 2368, VOL. 95] 